\title{
Prevalence of Salmonella enterica, Listeria monocytogenes, and pathogenic Escherichia coli in bulk tank milk and milk filters from US dairy operations in the National Animal Health Monitoring System Dairy 2014 study
}

\author{
Jakeitha L. Sonnier, ${ }^{*}$ Jeffrey S. Karns, ${ }^{*}$ Jason E. Lombard,† Christine A. Kopral,† Bradd J. Haley, ${ }^{*}$ \\ Seon-Woo Kim, ${ }^{*}$ and Jo Ann S. Van Kessel ${ }^{* 1}$ \\ *Environmental Microbial and Food Safety Laboratory, USDA, Agricultural Research Service, Beltsville, MD 20705 \\ †Center for Epidemiology and Animal Health, USDA, Animal and Plant Health Inspection Service, Veterinary Services, Fort Collins, CO 80526
}

\begin{abstract}
The dairy farm environment is a well-documented reservoir for zoonotic pathogens such as Salmonella enterica, Shiga-toxigenic Escherichia coli, and Listeria monocytogenes, and humans may be exposed to these pathogens via consumption of unpasteurized milk and dairy products. As part of the National Animal Health Monitoring System Dairy 2014 study, bulk tank milk (BTM, $\mathrm{n}=234)$ and milk filters $(\mathrm{n}=254)$ were collected from a total of 234 dairy operations in 17 major dairy states and analyzed for the presence of these pathogens. The invA gene was detected in samples from $18.5 \%$ of operations and Salmonella enterica was isolated from $18.0 \%$ of operations. Salmonella Dublin was detected in $0.7 \%$ of operations. Sixteen Salmonella serotypes were isolated, and the most common serotypes were Cerro, Montevideo, and Newport. Representative Salmonella isolates $(\mathrm{n}=137)$ were tested against a panel of 14 antimicrobials. Most (85\%) were pansusceptible; the remaining were resistant to 1 to 9 antimicrobials, and within the resistant strains the most common profile was resistance to ampicillin/clavulanic acid, ampicillin, cefoxitin, ceftiofur, ceftriaxone, chloramphenicol, streptomycin, sulfisoxazole, and tetracycline. Listeria spp. were isolated from $19.9 \%$ of operations, and $L$. monocytogenes was isolated from $3.0 \%$ of operations. Serogroups $1 / 2 \mathrm{a}$ and $1 / 2 \mathrm{~b}$ were the most common, followed by $4 \mathrm{~b}$ and $4 \mathrm{a}$. One or more $E$. coli virulence genes were detected in the BTM from $30.5 \%$ of operations and in the filters from $75.3 \%$ of operations. A combination of $s t x_{2}$, eaeA, and $\gamma$-tir genes was detected in the BTM from $0.5 \%$ of operations and in the filters from $6.6 \%$ of operations. The results of this study indicate an
\end{abstract}

Received July 21, 2017.

Accepted October 26, 2017.

${ }^{1}$ Corresponding author: joann.vankessel@ars.usda.gov appreciable prevalence of bacterial pathogens in BTM and filters, including serovars known to infect humans. Key words: bulk tank milk, Salmonella enterica, zoonotic, Listeria monocytogenes

\section{INTRODUCTION}

Each year in the United States, foodborne illnesses affect approximately 48 million people. The effect of these infections is substantial, with an economic burden of over $\$ 15$ billion when costs such as medical expenses and lost wages are considered (Scallan et al., 2011). In 2015, according to the Foodborne Diseases Active Surveillance Network (FoodNet), 18,375 laboratoryconfirmed cases of foodborne illness were attributed to bacterial pathogens (CDC, 2017a). The most common bacterial pathogens causing serious illness are nontyphoidal Salmonella, Shiga-toxigenic Escherichia coli (STEC) O157, Listeria monocytogenes, and Campylobacter spp. (Scallan et al., 2011). These species, along with non-O157 STEC, are sometimes associated with nonpasteurized dairy products and undercooked ground beef (Oliver et al., 2009; USDA FSIS, 2016a). Based on a compilation of raw milk-associated outbreaks in the United States from 1993 to 2006, Langer et al. (2012) determined that most dairy-related outbreaks were associated with the consumption of nonpasteurized milk, and that outbreaks attributed to raw dairy products were approximately 150 times more frequent, based on the unit of consumption, than those attributed to pasteurized milk or milk products. Notably, a disproportionate number of affected individuals were very young (under age 20) and their illnesses were especially severe.

Despite the risk of foodborne illness, consumption of unpasteurized milk and dairy products continues to rise (Mungai et al., 2015). Consumer trends favor unprocessed or less-processed foods and supporting local farms; additionally, some proponents believe raw milk may provide more health benefits than pasteurized milk 
(Katafiasz and Bartlett, 2012; Robinson et al., 2014). As sales have increased, so have reports of outbreaks associated with raw milk and raw milk cheeses. The number of documented outbreaks increased from 30 between 2007 and 2009 to 51 outbreaks between 2010 and 2012 (Mungai et al., 2015). Furthermore, outbreaks are more frequently reported in regions that allow raw milk sales than in areas where raw milk sales are banned. According to a 2011 survey by the National Association of State Departments of Agriculture (NASDA) and the National Association of Dairy Regulatory Officials, 30 states allow raw milk sales for human consumption. State rules may allow for sales in retail stores, farmers markets, or on-the-farm-only sales, whereas in other states sales are managed through cow share purchases (NASDA, 2011). Therefore, it is important to survey and characterize pathogens in raw milk at the farm to understand the potential public health threats.

The USDA's National Animal Health Monitoring System (NAHMS) conducts periodic surveys of representative US dairy farms to collect data on animal health, management, and productivity. Previous studies were conducted in 1996, 2002, and 2007. Fecal samples were collected and tested for the presence of Salmonella and E. coli O157 in the 1996 Dairy study (USDA APHIS, 1998). Bulk tank milk (BTM) samples were incorporated in the 2002 study, and milk filters, which allow for greater sensitivity in detecting some bacterial pathogens, were also collected in the 2007 and 2014 studies (Van Kessel et al., 2004, 2008, 2011; Latorre et al., 2011; USDA APHIS, 2011).

The objective of this study was to determine the prevalence of STEC, Salmonella enterica, and L. monocytogenes, as well as antimicrobial resistance patterns in $S$. enterica isolates, in BTM and milk filters from US dairies.

\section{MATERIALS AND METHODS}

\section{Sample Collection}

Samples were collected as part of the NAHMS Dairy 2014 study. For selection of participating operations, data from the USDA's National Agricultural Statistics Service were used to identify a stratified random sample of dairy operations as candidates for survey participation. The survey design was a stratified random sample with unequal selection probabilities to ensure the inclusion of large dairy operations $(\geq 500$ cows) and organic operations. Producers reporting 1 or more milk cows in inventory on January 1, 2014 ( $\mathrm{n}=$ $3,500)$, were included in phase I in which National Agricultural Statistics Service enumerators administered a general management questionnaire to participating producers $(\mathrm{n}=1,191)$. In phase II of the study, federal and state veterinary medical officers or animal health technicians administered an additional questionnaire to operations that had completed phase I of the survey and reported $\geq 30$ milk cows on January 1, 2014 (n $=265$ ). Participating operations were located in 17 major dairy states: California, Colorado, Idaho, Texas, and Washington from the western region, and Indiana, Iowa, Kentucky, Michigan, Minnesota, Missouri, New York, Ohio, Pennsylvania, Vermont, Virginia, and Wisconsin from the eastern region of the country. These states represented $80.5 \%$ of dairy herds and $81.3 \%$ of dairy cows in the United States. Operations were classified into 3 herd size categories based on the number of cows: small (30-99 cows), medium (100-499 cows), and large (500 or more cows).

Samples of BTM (50-150 mL) and milk filters representing 1 complete herd milking cycle were aseptically collected from 234 participating operations that completed phase II of the study. Samples were collected from March through July of 2014 and shipped overnight with cold packs to the USDA's Agricultural Research Service (Beltsville, MD) laboratory, where they were processed upon receipt.

\section{Bacteriological Methods}

Aliquots of the BTM samples from a single operation were combined (up to $100 \mathrm{~mL}$ ) and added to enrichment broth specific for the target species. As previously described, milk filters were aseptically cut into small $\left(30-50 \mathrm{~cm}^{2}\right)$ pieces, placed in a filtered stomacher bag, weighed, and diluted 1:1 (wt/wt) with $1 \%$ buffered peptone water (Van Kessel et al., 2011). When multiple filters were collected from an operation, filters were combined into groups of $\leq 6$ filters and each filter group was processed separately. The filters were then pummeled in an automatic bag mixer, twice for $2 \mathrm{~min}$ each, with repositioning of filter pieces to the bottom of the bag between the first and second mixes (Van Kessel et al., 2008, 2011).

For enrichment of E. coli, $5 \mathrm{~mL}$ of BTM or filter filtrate was added to $5 \mathrm{~mL}$ of double-strength EC medium enrichment broth (BD Diagnostics, Sparks, MD) and incubated at $42^{\circ} \mathrm{C}$ for 18 to $24 \mathrm{~h}$. After incubation and mixing, $2 \mathrm{~mL}$ was centrifuged for $2 \mathrm{~min}$ at $12,000 \times$ $g$ at $25^{\circ} \mathrm{C}$, and the supernatant was discarded. The pelleted biomass was resuspended in $500 \mu \mathrm{L}$ of $1 \times$ freezing medium for cells (Schleif and Wensink, 1981) and stored at $-80^{\circ} \mathrm{C}$. In parallel, $1.5 \mathrm{~mL}$ of enrichment was centrifuged for $2 \mathrm{~min}$ at $12,000 \times g$ at $25^{\circ} \mathrm{C}$ for nucleic acid extraction and PCR analysis; the supernatant was removed and the pelleted biomass was stored at $-20^{\circ} \mathrm{C}$. The DNA was extracted using InstaGene Matrix (Bio- 
Rad Laboratories, Hercules, CA) according to the manufacturer's instructions and stored at $-20^{\circ} \mathrm{C}$.

To identify the potential for pathogenic strains within the E. coli population, the E. coli enrichment DNA extracts were screened for 4 virulence genes using a real-time PCR assay targeting Shiga-toxin genes 1 and $2\left(s t x_{1}, s t x_{2}\right)$, intimin (eaeA), and the gamma allele of the translocated intimin receptor $(\gamma$-tir). Assays were conducted on an MX3005P qPCR instrument (Stratagene, La Jolla, CA) as described previously (Van Kessel et al., 2011).

Salmonella isolation was performed in a 2-step enrichment process, similar to the method described in the Biological Analytical Manual (Andrews et al., 2016) with the exclusion of a parallel enrichment in Rappaport-Vassiliadis medium. First, $25 \mathrm{~mL}$ of BTM or filter filtrate was added to $225 \mathrm{~mL}$ of lactose broth (Acumedia, Lansing, MI) and incubated at $37^{\circ} \mathrm{C}$ for 18 to $24 \mathrm{~h}$. Then, $1 \mathrm{~mL}$ of the lactose broth enrichment was transferred to $9 \mathrm{~mL}$ of tetrathionate broth (Acumedia) and incubated for 18 to $24 \mathrm{~h}$ at $37^{\circ} \mathrm{C}$. Approximately $2 \mathrm{~mL}$ of enrichment was processed and DNA was extracted as described for E. coli enrichments. The DNA extracts were screened for the invA gene by real-time PCR, as previously described (Karns et al., 2005; Van Kessel et al., 2011). When the invA gene was detected in the enrichments, preserved biomass $(\sim 10 \mu \mathrm{L})$ was streaked onto XLT4 agar (XLT4 agar base with XLT4 supplement; Acumedia) and incubated at $37^{\circ} \mathrm{C}$ for $48 \mathrm{~h}$. Plates were scored at both 24 and $48 \mathrm{~h}$ for presumptive Salmonella (black) colonies. When presumptive Salmonella were not identified in invA-positive enrichments, the enrichments were streaked onto brilliant green (BG) agar (BD Diagnostics). Presumptive Salmonella (black isolates on XLT4 or pink isolates on BG; at least 5 per sample, when available) and red or yellow isolates from XLT4 (up to 5 per sample) were transferred to XLT4, $\mathrm{BG}$, and L-agar (Lennox Broth base with 1.5\% agar; Acumedia) and incubated for $24 \mathrm{~h}$ at $37^{\circ} \mathrm{C}$. Isolates exhibiting the Salmonella phenotype (black on XLT4, pink on BG, or both), as well as isolates that were red or yellow on XLT4 and pink on BG, were preserved for future analysis. Biomass from the L-agar plates was transferred to a vial containing $500 \mu \mathrm{L}$ of $1 \times$ freezing medium, vortexed, and stored at $-80^{\circ} \mathrm{C}$. Presumptive Salmonella isolates (2 per sample, when available) were also cultured on L-agar slants and shipped to the National Veterinary Services Laboratories in Ames, Iowa, for serotype identification.

Because of reports that Salmonella Dublin is not easily identified by traditional culture techniques used for isolating S. enterica (Veling et al., 2002; Nielsen et al., 2004), a PCR assay was developed to specifi- cally target this serovar. The primers and probe were designed using Insignia (http://insignia.cbcb.umd.edu; Phillippy et al., 2007) based on prokaryote genomes in the Insignia database in October 2013. Specificity to S. enterica serovar Dublin was further confirmed with the NCBI Primer-BLAST program (Ye et al., 2012) using the RefSeq representative genomes database. The PCR reactions consisted of $2 \mu \mathrm{L}$ of DNA, $25 \mu \mathrm{L}$ of a qPCR master mix with low ROX (Eurogentec Inc., San Diego, CA), and $23 \mu \mathrm{L}$ of a primer/probe mixture containing $300 \mathrm{n} M$ of each primer (SD-1C forward: 5'-GTTTTCAGTCCGGTGCTTGA-3', SD-1C reverse: 5'-GGCAACTCTCCAGACCATT-3'), $250 \mathrm{n} M$ probe (SD-1 CY5: 5'-TTCCCGTTGTCGCGTCTCCA-3'), and $50 \mu \mathrm{g} / \mathrm{mL}$ of BSA (final concentrations). The DNA from all invA-positive enrichments was analyzed with the Salmonella Dublin-specific real-time PCR assay, using an MX3005P qPCR instrument (Stratagene). The thermocycler program included a 10-min warm up and enzyme activation step at $95^{\circ} \mathrm{C}$ and 40 cycles of $95^{\circ} \mathrm{C}$ for $30 \mathrm{~s}, 55^{\circ} \mathrm{C}$ for $60 \mathrm{~s}$, and $72^{\circ} \mathrm{C}$ for $60 \mathrm{~s}$, followed by a $72^{\circ} \mathrm{C}, 10$-min final extension step. The fluorescence of the CY5 channel was read during the plateau step. Enrichments with cycle threshold values of $<37$ were considered positive.

Isolation of Listeria spp. was performed as previously published (Van Kessel et al., 2011), except 5 mL of BTM or filter filtrate was added to $5 \mathrm{~mL}$ of double-strength Modified Listeria Enrichment Broth (BD Diagnostics). Enrichments were incubated for $48 \mathrm{~h}$ at $37^{\circ} \mathrm{C}$, aliquots were centrifuged, and preservation was conducted as described for E. coli enrichments.

The enrichment broths $(50 \mu \mathrm{L})$ were also streaked onto Modified Oxford agar (MOX, BD Diagnostics), supplemented with cefixime $(50 \mu \mathrm{g} / \mathrm{mL}$, final concentration; Sigma-Aldrich, St. Louis, MO), and incubated at $37^{\circ} \mathrm{C}$. Plates were scored at $24 \mathrm{~h}$ and at $48 \mathrm{~h}$. Presumptive Listeria isolates (gray, sometimes dimpled colonies, that hydrolyzed esculin; up to 24 per sample) were transferred to MOX agar, Palcam agar (BD Diagnostics), a chromogenic agar (R\&F Laboratories, Downers Grove, IL), and trypticase soy agar with $0.6 \%$ yeast extract (Acumedia). Isolates exhibiting both growth and esculin hydrolysis on MOX and Palcam agars, and growth on trypticase soy-yeast extract agars were scored as Listeria spp. Blue colonies on the chromogenic media were scored as L. monocytogenes and white colonies were scored as non-monocytogenes Listeria spp. Isolates of the Listeria spp. and L. monocytogenes phenotypes were preserved for further analyses. For isolate preservation, biomass from the Palcam agar plates was transferred to vials containing $1 \mathrm{~mL}$ of trypticase soy broth. The cultures were incubated for 
$48 \mathrm{~h}$ at $37^{\circ} \mathrm{C}$, and then centrifuged and preserved in the same manner as described for E. coli isolates (Van Kessel et al., 2011).

For presumptive L. monocytogenes isolates, DNA was extracted using InstaGene Matrix according to the manufacturer's instructions, and serogroups were determined following the PCR method of Doumith et al. (2004), with minor modifications: AmpliTaq Gold reagents (Applied Biosystems, Foster City, CA) were used, a 10-min heat activation step was added to the thermal program, and the 5-plex was separated into 2 duplexes (lmo0737 and ORF2819, and $l m o 1118$ and ORF2110) and 1 single-plex reaction (prs). Isolates exhibiting profiles other than those reported by Doumith et al. (2004) were further analyzed using a lineage PCR method described by Ward et al. (2004), with similar modifications. The lineage 1 and 3 assays were run as a duplex, and the lineage 2 assay was run independently. AmpliTaq Gold reagents were used and the thermal cycler program was extended with a 10-min enzyme activation step and an additional 5 run cycles, totaling 30 cycles.

\section{Antimicrobial Susceptibility Testing}

All Salmonella isolates were pre-screened for resistance to 7 antimicrobials by transferring biomass from BG agar plates onto Mueller Hinton agar plates (Acumedia) that were supplemented with 1 of the following antimicrobials: $32 \mu \mathrm{g} / \mathrm{mL}$ ampicillin, $32 \mu \mathrm{g} /$ $\mathrm{mL}$ chloramphenicol, $16 \mu \mathrm{g} / \mathrm{mL}$ tetracycline, $64 \mu \mathrm{g} /$ $\mathrm{mL}$ streptomycin, $64 \mu \mathrm{g} / \mathrm{mL}$ kanamycin, $2 \mu \mathrm{g} / \mathrm{mL}$ ciprofloxacin (Sigma-Aldrich), or $32 \mu \mathrm{g} / \mathrm{mL}$ cefoxitin (Gold Bio, St. Louis, MO). In most cases, 2 isolates per sample, including at least 1 isolate per serotype and per resistance profile, were tested for sensitivity to the National Antimicrobial Resistance Monitoring System (NARMS) panel of 14 antimicrobials (CMV3AGNF) using a Sensititre ARIS automated microdilution system (Trek Diagnostics Systems, Cleveland, OH). Only 1 Salmonella isolate was obtained in each of 4 samples and 3 isolates were tested from 1 sample. Antimicrobial susceptibility was determined using the following resistance breakpoints, based on the Clinical and Laboratory Standards Institute interpretive criteria (CLSI, 2012; FDA, 2015): $\geq 32 \mu \mathrm{g} / \mathrm{mL}$ cefoxitin $($ FOX),$\geq 32 \mu \mathrm{g} / \mathrm{mL}$ azithromycin (AZI), $\geq 32 \mu \mathrm{g} /$ $\mathrm{mL}$ chloramphenicol $(\mathbf{C H L}), \geq 16 \mu \mathrm{g} / \mathrm{mL}$ tetracycline (TET), $\geq 4 \mu \mathrm{g} / \mathrm{mL}$ ceftriaxone (AXO), $\geq 32 / 16 \mu \mathrm{g} /$ $\mathrm{mL}$ amoxicillin/clavulanic acid (AUG), $\geq 1 \mu \mathrm{g} / \mathrm{mL}$ ciprofloxacin $(\mathbf{C I P}), \geq 16 \mu \mathrm{g} / \mathrm{mL}$ gentamicin $($ GEN), $\geq 32$ $\mu \mathrm{g} / \mathrm{mL}$ nalidixic acid (NAL), $\geq 8 \mu \mathrm{g} / \mathrm{mL}$ of ceftiofur (TIO), $\geq 512 \mu \mathrm{g} / \mathrm{mL}$ sulfisoxazole (FIS), $\geq 4 / 76 \mu \mathrm{g} /$ $\mathrm{mL}$ trimethoprim/sulfamethoxazole $(\mathbf{S X T}), \geq 32 \mu \mathrm{g} /$
$\mathrm{mL}$ ampicillin (AMP), and $\geq 32 \mu \mathrm{g} / \mathrm{mL}$ streptomycin (STR). The following quality control strains were also run to verify panel performance: Enterococcus faecalis ATCC 29212, E. coli ATCC 25922, and Pseudomonas aeruginosa ATCC 27853.

\section{Statistical Analysis}

The operation-level prevalence of S. enterica, Listeria spp., L. monocytogenes, and E. coli virulence genes are presented as statistically weighted percentages to indicate national prevalence estimates. The weighted prevalence was calculated using statistical software (SUDAAN, Release 11.0.1, 2013; Research Triangle Institute, Research Triangle Park, NC) which accounted for the operations' probability of selection and adjusted for nonresponse. Selection weights and nonresponse adjustments were based on state and herd size. Unless otherwise stated, all prevalence estimates are provided as weighted prevalence. Estimates on percentage of positive samples were conducted using SAS (version 9.4, SAS Institute Inc., Cary, NC). Prevalence across herd size, region, and operation type was compared using the Wald F-test. Serotype data, which represents a small number of positive samples, are presented as unweighted estimates.

\section{RESULTS}

\section{Sample Distribution}

Between March 18 and July 16, 2014, a total of 488 samples (234 BTM and 254 milk filters) were collected from 234 operations in 17 states (Table 1). There were 63 small herds, 71 medium herds, and 100 large herds. Of these, 19 were organic and 215 were conventionally managed. Both BTM and filter samples were collected from 231 operations, but only BTM (no filter) was collected from 3 operations. Multiple filters (as many as 20) were collected from 67 operations, and 17 operations had too many filters to be processed as a single sample. These filters were grouped into manageable numbers (maximum of 6 filters per group) and processed as single samples.

\section{Salmonella}

The invA gene of $S$. enterica was detected by realtime PCR in 72 of 488 samples (18.5\%), including 11 BTM and 61 filters (Table 2). Samples that were invA-positive were subsequently tested with a second real-time PCR analysis targeting the serotype, Dublin. In total, 4 samples (1 BTM and 3 filters; 0.7\%) were positive for Salmonella Dublin (Table 3). When 
Table 1. States of origin and distribution of bulk tank milk (BTM) and milk filters

\begin{tabular}{|c|c|c|c|c|c|c|}
\hline State & No. of samples & No. of operations & Milk total & Filter total & Milk-filter pairs & Milk, no filter ${ }^{1}$ \\
\hline $\mathrm{CO}$ & 13 & 5 & 5 & 8 & 5 & 0 \\
\hline ID & 13 & 6 & 6 & 7 & 6 & 0 \\
\hline IA & 24 & 12 & 12 & 12 & 12 & 0 \\
\hline KY & 2 & 1 & 1 & 1 & 1 & 0 \\
\hline MI & 35 & 18 & 18 & 17 & 17 & 1 \\
\hline $\mathrm{OH}$ & 20 & 10 & 10 & 10 & 10 & 0 \\
\hline PA & 38 & 19 & 19 & 19 & 19 & 0 \\
\hline $\mathrm{TX}$ & 2 & 1 & 1 & 1 & 1 & 0 \\
\hline VT & 2 & 1 & 1 & 1 & 1 & 0 \\
\hline VA & 15 & 8 & 8 & 7 & 7 & 1 \\
\hline WA & 29 & 11 & 11 & 18 & 11 & 0 \\
\hline
\end{tabular}

${ }^{1}$ All milk filters had a corresponding BTM sample.

all PCR-positive enrichments were streaked onto XLT4 agar, Salmonella was isolated from 70 samples, including 10 BTM samples and 60 filters (18\%; Table 2). The prevalence of Salmonella, based on both detection of the invA gene and isolation, was higher $(P=0.0001)$ in large (>500 cows) herds than in small (30-99 cows) or medium (100-499 cows) herds (Table 4). No regional differences in Salmonella prevalence were observed by either invA gene detection or isolation $(P=0.3322$ and $P=0.3722$, respectively). Also, no statistically significant differences were observed in the percentage of operations that were positive for Salmonella between operations that were identified as organic and those that were classified as conventional operations, grazing operations, or other types of operations (Table 5).

Sixteen different serotypes were identified in the 140 Salmonella isolates including Anatum, Bareilly, Bredeney, Cerro, Derby, Dublin, Give, Kentucky, Liverpool, Meleagridis, Montevideo, Muenchen, Muenster, Newport, Oranienburg, and Orion (Table 6). Cerro was the most prevalent serotype and it was isolated from approximately half (50.8\%) of the Salmonella-positive operations. Although only 1 serotype was isolated from most Salmonella-positive operations, multiple serotypes were detected in samples from 8 operations. In 4 of these operations, the serotypes identified in the BTM were different than the serotypes identified in the milk filter. The serotype combinations included Cerro (BTM) and Montevideo (filters); Dublin (BTM) and Newport (filters); Orion and Bareilly (BTM) and Newport (filters); and Cerro (BTM) and both Bredeney and Muenchen (filters). Filters from 4 additional operations yielded more than 1 serotype: Cerro and Give (1 operation), Cerro and Kentucky (1 operation), and Cerro and Montevideo (2 operations).

Based on pre-screening of 376 Salmonella isolates from the 70 culture-positive samples (10 BTM and 60 filters) for resistance to each of 7 antimicrobials, representative Salmonella isolates $(\mathrm{n}=137)$, including at least 1 per serotype and per resistance profile, were

Table 2. Weighted percentage of US dairy operations positive for Salmonella by PCR and culture in bulk tank milk and milk filters

\begin{tabular}{|c|c|c|c|c|}
\hline Item & \multicolumn{2}{|l|}{ PCR } & \multicolumn{2}{|l|}{ Culture } \\
\hline Positive milk & 3.1 & 1.4 & 3.0 & 1.4 \\
\hline Positive milk and positive filter & 2.6 & 1.3 & 2.6 & 1.3 \\
\hline Negative milk and positive filter & 15.4 & 2.9 & 15.0 & 2.9 \\
\hline Positive milk and negative filter & 0.5 & 0.4 & 0.4 & 0.4 \\
\hline Negative milk and no filter & 0.3 & 0.2 & 0.3 & 0.2 \\
\hline Negative milk and negative or no filter & 81.5 & 3.1 & 82.0 & 3.1 \\
\hline Any positive sample & 18.5 & 3.1 & 18.0 & 3.1 \\
\hline
\end{tabular}


Table 3. Weighted percentage of US dairy operations positive for both invA and Salmonella Dublin by PCR in bulk tank milk and milk filters

\begin{tabular}{lcc}
\hline Item & Weighted \% of operations & SE \\
\hline Total positive milk & 0.3 & 0.3 \\
Total positive filter & 0.4 & 0.3 \\
Positive milk, negative filter & 0.3 & 0.3 \\
Positive milk, no filter & 0.0 & 0.0 \\
Positive filter, negative milk & 0.4 & 0.3 \\
Positive milk and filter & 0.0 & 0.0 \\
Negative milk, no filter & 0.0 & 0.0 \\
Operations with any positive sample & 0.7 & 0.4 \\
\hline
\end{tabular}

selected for sensitivity testing on the NARMS panel of 14 antimicrobials. Of these, 118 isolates from 49 operations (9 BTM and 53 filters) were susceptible to all antimicrobials on the panel (Table 7). Fourteen isolates (10 Newport, 2 Muenchen, and 2 Dublin), representing 8 samples (1 BTM and 7 filters) from 5 operations were multi-drug resistant (MDR) to the same 9 antimicrobials: AUG/AMP/FOX/TIO/AXO/CHL/STR/FIS/ TET. Two Salmonella Dublin isolates from 1 filter were resistant to AUG/AMP/FOX/TIO/AXO/STR, and 3 isolates, 2 Salmonella Give and 1 Salmonella Newport from 2 different filters, were resistant to CHL/STR/ FIS/TET. In addition, 2 Salmonella Cerro isolates from 2 separate filters were resistant to STR.

In most cases, isolates from the same operation were resistant to the same antimicrobial agents, but there were 5 exceptions. In 1 operation, a pansusceptible Salmonella Cerro was isolated from the BTM, while a pansusceptible Salmonella Bredeney and an MDR-9 (resistant to 9 antimicrobials) Salmonella Muenchen were isolated from the corresponding filters. In another operation, an MDR-4 Salmonella Give was isolated from 1 filter group, whereas a pansusceptible Salmonella Cerro was isolated from a different filter group from the same operation. Additionally, 2 Salmonella Newport isolates from 1 filter sample exhibited different susceptibility profiles: 1 isolate was MDR- 4 whereas the other was MDR-9. Similarly, in 2 operations, 1 filter sample yielded 2 Salmonella Cerro isolates with different profiles: 1 isolate was STR resistant, whereas the other isolate was pansusceptible.

\section{E. coli}

One or more $E$. coli virulence genes were detected in 293 of the 488 samples, including 77 BTM $(30.5 \%)$ and 216 filters (75.3\%; Table 8). The Shiga-toxin gene, stx $x_{1}$, was detected in 18 BTM (6.0\%) and 153 filters (46.4\%) and $s t x_{2}$ was detected in 11 BTM $(6.3 \%)$ and 74 filters $(26.5 \%)$. The eaeA gene was detected in 54 BTM samples and 197 filters (17.4 and $63.7 \%$, respectively). Three BTM (1.0\%) and 60 filters $(18.4 \%)$ were positive for both stx genes and 1 BTM $(0.5 \%)$ and 29 filters $(6.6 \%)$ were positive for $s t x_{2}$, eaeA, and $\gamma$-tir. None of the milk samples were positive for all 4 virulence genes, but the $s t x_{1}, s t x_{2}, e a e A$, and $\gamma$-tir genes were all detected in each of 27 filters $(6.1 \%)$.

\section{Listeria}

Listeria spp. were isolated from 53 samples, including $6 \operatorname{BTM}(2.7 \%)$ and 47 filters $(19.1 \%) ;$ L. monocytogenes was isolated from 18 samples [4 BTM (1.1\%) and 14 filters $(2.5 \%)$ ] representing 14 operations (Table 9). The prevalence of Listeria spp. was lower in large herds than in small or medium herds, but this numerical dif-

Table 4. Percentage of US dairy operations positive for the Salmonella, Listeria spp., and Listeria monocytogenes in bulk tank milk or milk filters by herd size and region

\begin{tabular}{|c|c|c|c|c|c|c|c|c|c|c|c|c|c|c|}
\hline \multirow[b]{3}{*}{ Item } & \multicolumn{6}{|c|}{ Herd size (no. of cows) } & \multicolumn{4}{|c|}{ Region } & & & & \\
\hline & \multicolumn{2}{|c|}{$\begin{array}{c}\text { Small } \\
(30-99)\end{array}$} & \multicolumn{2}{|c|}{$\begin{array}{c}\text { Medium } \\
(100-499)\end{array}$} & \multicolumn{2}{|c|}{$\begin{array}{l}\text { Large } \\
(500+)\end{array}$} & \multicolumn{2}{|c|}{ West } & \multicolumn{2}{|c|}{ East } & \multicolumn{2}{|c|}{$\begin{array}{c}\text { All } \\
\text { operations }\end{array}$} & \multicolumn{2}{|c|}{$\begin{array}{l}\text { Wald } F \\
P \text {-value }\end{array}$} \\
\hline & $\%$ & SE & $\%$ & $\mathrm{SE}$ & $\%$ & $\mathrm{SE}$ & $\%$ & $\mathrm{SE}$ & $\%$ & $\mathrm{SE}$ & $\%$ & $\mathrm{SE}$ & Herd size & Region \\
\hline Salmonella (PCR) & $9.3^{\mathrm{a}}$ & $(4.6)$ & $21.5^{\mathrm{a}}$ & $(5.8)$ & $40.6^{\mathrm{b}}$ & $(5.1)$ & 13.1 & $(5.0)$ & 19.2 & $(3.5)$ & 18.6 & $(3.2)$ & 0.0001 & 0.3322 \\
\hline Salmonella (culture) & $9.3^{\mathrm{a}}$ & $(4.6)$ & $20.2^{\mathrm{a}}$ & $(5.7)$ & $40.3^{\mathrm{b}}$ & $(5.2)$ & 13.1 & $(5.0)$ & 18.7 & $(3.5)$ & 18.1 & $(3.2)$ & 0.0001 & 0.3722 \\
\hline
\end{tabular}

$\overline{\mathrm{a}, \mathrm{b}}$ Percentages with different superscripts within the same row differ among herd size categories $(P \leq 0.05)$. 
Table 5. Percentage of US dairy operations positive for Salmonella, Listeria spp., and Listeria monocytogenes in bulk tank milk or milk filters by operation type

\begin{tabular}{|c|c|c|c|c|c|}
\hline \multirow[b]{3}{*}{ Item } & \multicolumn{4}{|c|}{ Operation type } & \multirow{3}{*}{$\begin{array}{l}\text { Wald } F \\
P \text {-value }\end{array}$} \\
\hline & \multicolumn{2}{|c|}{ Organic } & \multicolumn{2}{|c|}{ Conventional/grazing/other } & \\
\hline & $\%$ & $\mathrm{SE}$ & $\%$ & $\mathrm{SE}$ & \\
\hline Salmonella (PCR) & 8.2 & 5.8 & 19.3 & 3.4 & 0.1303 \\
\hline Salmonella (culture) & 8.2 & 5.8 & 18.9 & 3.4 & 0.1449 \\
\hline Listeria spp. & 21.4 & 9.2 & 19.9 & 3.6 & 0.8816 \\
\hline L. monocytogenes & 4.5 & 4.4 & 2.9 & 0.9 & 0.7220 \\
\hline
\end{tabular}

ference was only significant at $P=0.0965$ level (Table 4). However, L. monocytogenes prevalence was higher $(P=0.0293)$ in the medium and large herds than it was in the small herds. No regional differences in Listeria spp. or $L$. monocytogenes prevalence were observed ( $P=0.1546$ and $P=0.1330$, respectively). Also, no statistically significant differences were observed in the percentage of operations that were positive for Listeria spp. or L. monocytogenes between operations that were identified as organic and those that were classified as conventional operations, grazing operations, or other types of operations (Table 5).

Based on PCR analysis, the serogroup was determined for a total of $43 \mathrm{~L}$. monocytogenes isolates (Table 10). Sixteen isolates were identified as serogroup $1 / 2 \mathrm{a}$, 10 isolates were $1 / 2 \mathrm{~b}, 7$ isolates were $4 \mathrm{a}$, and 5 isolates were $4 \mathrm{~b}$. Five isolates did not conform to profiles report- ed by Doumith et al. (2004). Four of these isolates were positive for the lmo0737, ORF2110, ORF2819, and prs genes and were classified as $4 \mathrm{~b}$, based on other studies where L. monocytogenes with this atypical PCR profile were further characterized (Huang et al., 2011; Leclercq et al., 2011; Laksanalamai et al., 2014). The fifth atypical isolate was positive for the lmo0737, ORF2110, and prs genes; this isolate could not be classified because no known corresponding serogroups have this profile. A lineage PCR (Ward et al., 2004) was used to further characterize the 5 atypical L. monocytogenes isolates. Three presumptive $4 \mathrm{~b}$ isolates were classified as lineage 1. Two isolates, 1 of each atypical profile, were positive for both lineage 2 and lineage 3 genes. Overall, the predominant serogroups were $1 / 2 \mathrm{a}(37.2 \%), 1 / 2 \mathrm{~b}(23.3 \%)$, and $4 \mathrm{~b} /$ presumptive $4 \mathrm{~b}(20.9 \%)$, and $4 \mathrm{a}$ comprised $16.3 \%$ of isolates tested.

Table 6. Salmonella enterica serotype distribution: number and unweighted prevalence (\%) of isolated serotypes from bulk tank milk and milk filters

\begin{tabular}{|c|c|c|c|c|c|c|c|c|c|c|}
\hline \multirow[b]{2}{*}{ Serotype } & \multicolumn{2}{|c|}{ Milk $^{1}$} & \multicolumn{2}{|c|}{ Filter $^{2}$} & \multicolumn{2}{|c|}{ Milk-filter pairs ${ }^{3}$} & \multicolumn{2}{|c|}{ Total samples } & \multicolumn{2}{|c|}{ Total operations } \\
\hline & No. & $\%^{4}$ & No. & $\%$ & No. & $\%$ & No. & $\%$ & No. & $\%$ \\
\hline Anatum & 0 & 0.0 & 0 & 0.0 & 1 & 20.0 & 2 & 0.4 & 1 & 0.4 \\
\hline Bareilly $^{5}$ & 1 & 16.7 & 0 & 0.0 & 0 & 0.0 & 1 & 0.2 & 1 & 0.4 \\
\hline Bredeney ${ }^{5}$ & 0 & 0.0 & 1 & 1.8 & 0 & 0.0 & 2 & 0.4 & 1 & 0.4 \\
\hline Cerro $^{5}$ & 3 & 50.0 & 27 & 49.1 & 3 & 60.0 & 36 & 7.4 & 33 & 14.1 \\
\hline Derby & 0 & 0.0 & 1 & 1.8 & 0 & 0.0 & 1 & 0.2 & 1 & 0.4 \\
\hline Dublin 5 & 1 & 16.7 & 1 & 1.8 & 0 & 0.0 & 2 & 0.4 & 2 & 0.9 \\
\hline Give $^{5}$ & 0 & 0.0 & 1 & 1.8 & 1 & 20.0 & 3 & 0.6 & 2 & 0.9 \\
\hline Kentucky $^{5}$ & 0 & 0.0 & 4 & 7.3 & 0 & 0.0 & 4 & 0.8 & 4 & 1.7 \\
\hline Liverpool & 0 & 0.0 & 1 & 1.8 & 0 & 0.0 & 1 & 0.2 & 1 & 0.4 \\
\hline Meleagridis & 0 & 0.0 & 2 & 3.6 & 0 & 0.0 & 3 & 0.6 & 2 & 0.9 \\
\hline Montevideo $^{5}$ & 0 & 0.0 & 8 & 14.5 & 0 & 0.0 & 9 & 1.8 & 8 & 3.4 \\
\hline Muenchen $^{5}$ & 0 & 0.0 & 1 & 1.8 & 0 & 0.0 & 2 & 0.4 & 1 & 0.4 \\
\hline Muenster & 0 & 0.0 & 1 & 1.8 & 0 & 0.0 & 1 & 0.2 & 1 & 0.4 \\
\hline Newport ${ }^{5}$ & 0 & 0.0 & 5 & 9.1 & 0 & 0.0 & 6 & 1.2 & 5 & 2.1 \\
\hline Oranienburg & 0 & 0.0 & 1 & 1.8 & 0 & 0.0 & 2 & 0.4 & 1 & 0.4 \\
\hline Orion $^{5}$ & 1 & 16.7 & 0 & 0.0 & 0 & 0.0 & 1 & 0.2 & 1 & 0.4 \\
\hline Total & 6 & & 54 & & 5 & & 76 & & 65 & \\
\hline
\end{tabular}

\footnotetext{
${ }^{1}$ Number of operations in which the serotype was identified only in a milk sample.

${ }^{2}$ Number of operations in which the serotype was identified only in a filter sample.

${ }^{3}$ Number of operations in which the serotype was identified in both the milk and filter samples.

${ }^{4}$ Percentage of total serotypes found in the respective samples.

${ }^{5}$ Multiple serotypes were identified in 8 operations.
} 
Table 7. Antimicrobial susceptibility profiles of Salmonella enterica isolates from bulk tank milk and milk filters

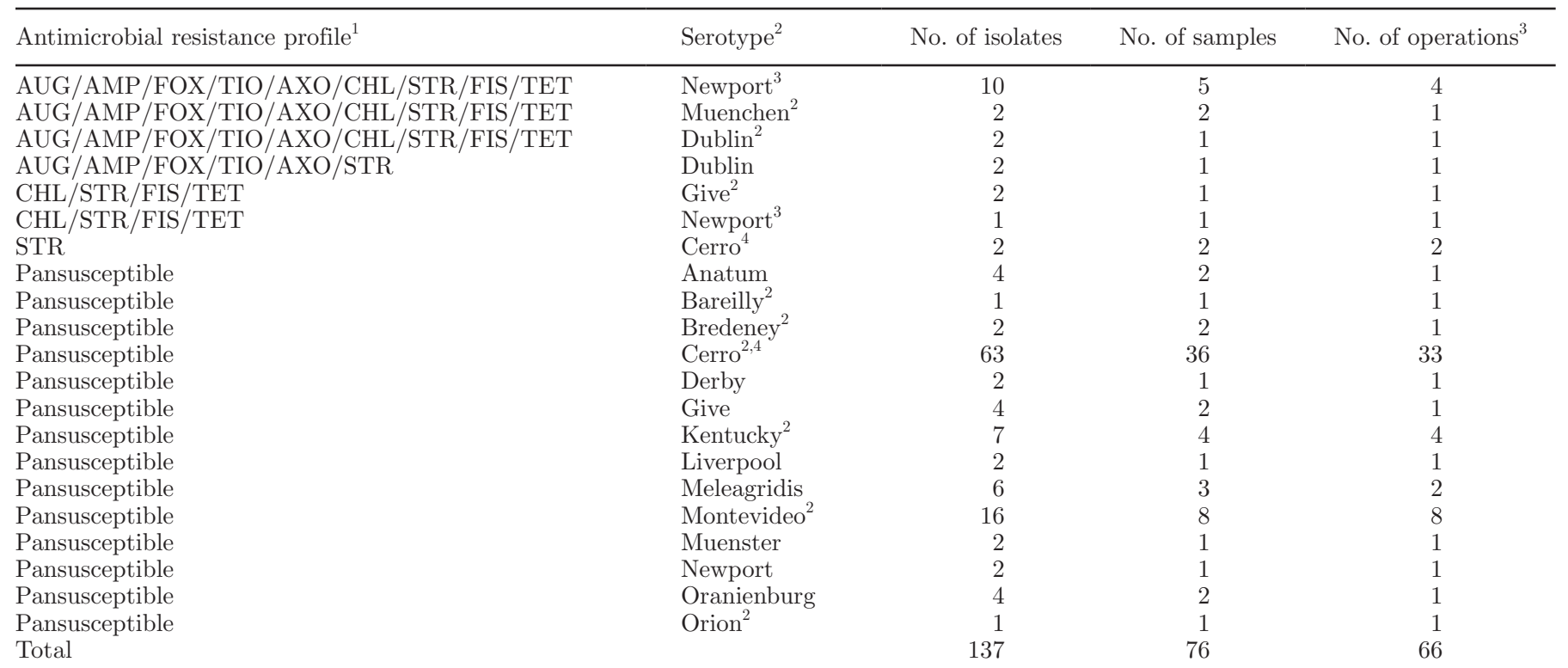

${ }^{1}$ Antimicrobial agents: $\mathrm{AUG}=$ amoxicillin/clavulanic acid; $\mathrm{AMP}=$ ampicillin; FOX $=$ cefoxitin; $\mathrm{TIO}=$ ceftiofur; $\mathrm{AXO}=$ ceftriaxone; $\mathrm{CHL}=$ chloramphenicol; STR = streptomycin; FIS = sulfisoxazole; and TET $=$ tetracycline.

${ }^{2}$ Multiple serotypes were isolated from 8 operations.

${ }^{3}$ Two Newport isolates, 1 multi-drug resistant (MDR) 4 and 1 MDR 9, were isolated from the same filter sample.

${ }^{4}$ In 2 operations 2 Cerro isolates, 1 pansusceptible and 1 STR resistant, were isolated from the same filter sample.

Listeria monocytogenes and Salmonella were both isolated from 5 operations. Samples from 2 of these operations were also identified as positive for Campylobacter spp. (del Collo et al., 2017). None of these 5 operations were positive for all $4 \mathrm{E}$. coli virulence genes.

\section{DISCUSSION}

The infrastructure of the NAHMS dairy studies has provided opportunities to sample BTM and milk filters and to assess the nationwide prevalence of select bacterial pathogens in milk. Previous NAHMS dairy studies have indicated variable prevalence of Salmonella (1.7$23.6 \%)$, L. monocytogenes (3.8-7.1\%), and E. coli carry- ing a combination of virulence genes of the E. coli $\mathrm{O} 157$ phenotype (1.1-6.3\%). Testing for Campylobacter spp. was added to the NAHMS 2014 Dairy study and has been previously reported. Campylobacter prevalence is high in dairy herds and was detected in the BTM or filters of $24.9 \%$ of operations (del Collo et al., 2017).

\section{Salmonella}

Nontyphoidal Salmonella species account for the majority of bacterial foodborne illnesses in the United States each year, and while there has been a decreased incidence of infections with specific serotypes such as Typhimurium, the overall incidence of salmonellosis

Table 8. Weighted percentage of US dairy operations positive for Escherichia coli virulence genes by PCR in bulk tank milk and milk filters

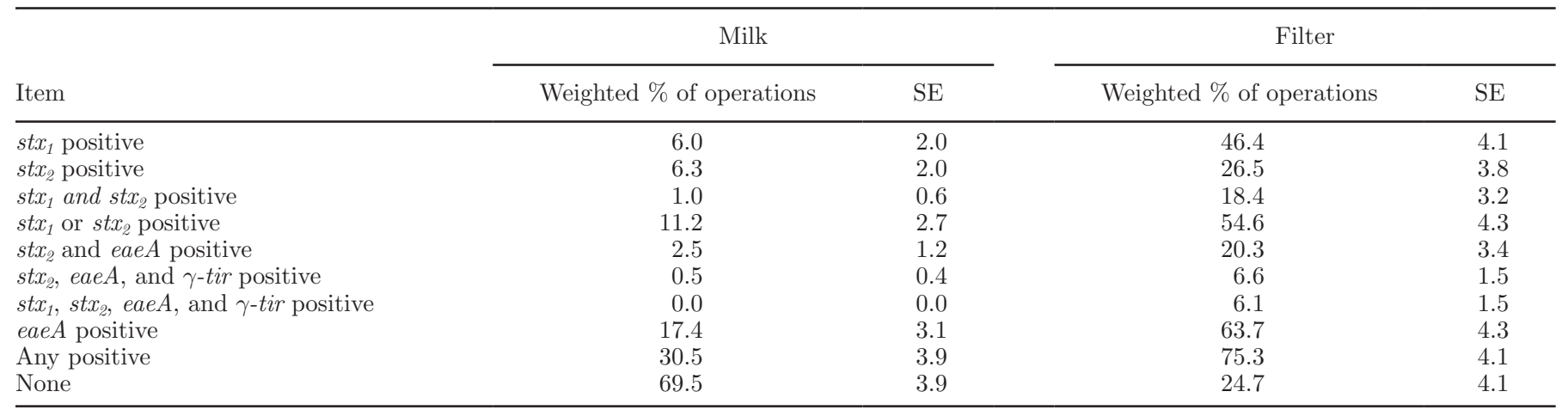


Table 9. Weighted percentage of US dairy operations positive for Listeria spp. or Listeria monocytogenes by culture in bulk tank milk and milk filters

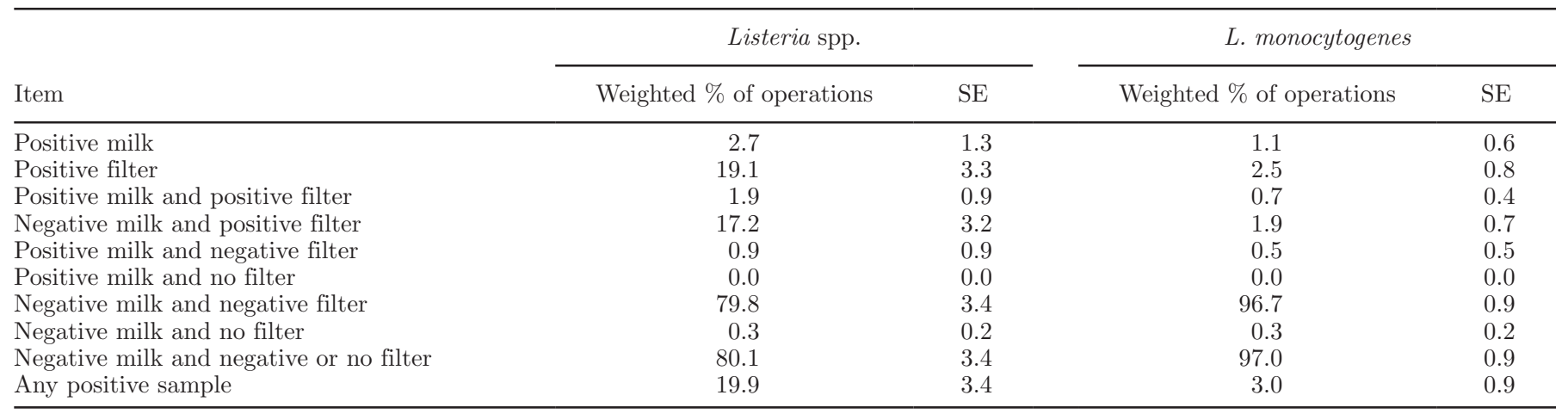

has been rather stable (Scallan et al., 2011; Crim et al., 2015). Based on detection of the invA gene, the prevalence of $S$. enterica in this study was $18.5 \%$ of operations. In the 2007 study, the invA gene was detected in $28.1 \%$ of operations, and in $2002,11.8 \%$ (unweighted) of milk samples were invA positive (Karns et al., 2005; Van Kessel et al., 2011). Sampling milk filters as well as BTM in the 2007 and 2014 studies, at least in part, explains the higher Salmonella prevalence in these surveys than the 2002 study; as previously reported, we have more frequently detected Salmonella in milk filters than in BTM from the same operation (Van Kessel et al., 2004, 2008; Karns et al., 2005).

Many of the over 2,500 known S. enterica serovars are host specific or host adapted and most of the 16 serovars identified in this study have previously been associated with dairy cattle. Some, such as Newport and Dublin, are known to affect animal health, whereas others, such as Cerro and Kentucky, are frequently isolated from asymptomatic animals. Cerro, Montevideo, and Newport were the most commonly isolated serotypes in this study and were isolated from 33,8 , and $5 \%$ of operations, respectively. In the 2002 study, 9 serotypes were identified, and Montevideo and Newport were the most common (0.8 and $0.5 \%$ of samples, respectively). Many more serotypes (23) were identified in 2007, and Cerro, Kentucky, and Muenster were predominant (23.6, 14.2, and $10.1 \%$ of total samples, respectively). Serotypes Cerro, Dublin, Meleagridis, Montevideo, Muenchen, and Newport were isolated from BTM or filters in all 3 studies.

These serovars have also been isolated from dairy cow feces and environmental samples. Wells et al. (2001), in a study of 91 dairies in 19 states, isolated Montevideo, Cerro, and Kentucky from fecal samples collected on farms and at cull cow markets. Serovars Newport, Muenchen, and Typhimurium were also prevalent in environmental samples collected from 11 Texas dairy farms, and both serovars Cerro and Kentucky have been frequently isolated from fecal and environmental samples on dairy farms in Pennsylvania and in New York (Van Kessel et al., 2007, 2012; Rodriguez-Rivera et al., 2014, 2016).

Comparisons of serovars found in cattle with those found in humans in the same geographic areas have suggested that human illness can potentially be at-

Table 10. Serogrouping PCR results of Listeria monocytogenes isolates from bulk tank milk and milk filters

\begin{tabular}{lccccc}
\hline Serogroup & Milk $^{1}$ & Filter $^{2}$ & Milk-filter pairs $^{3}$ & Total no. of samples $^{4}$ & Total no. of operations $^{2}$ \\
\hline $1 / 2 \mathrm{a}$ & 0 & 3 & 2 & 7 & 4 \\
$1 / 2 \mathrm{~b}$ & 1 & 3 & 0 & 2 & 4 \\
a & 0 & 2 & 0 & 4 & 2 \\
4b & 0 & 2 & 1 & 4 & 2 \\
Atypical 4b, L1 & 0 & 2 & 0 & 1 & 3 \\
Atypical 4b, L2 $+\mathrm{L3}^{5}$ & 0 & 1 & 0 & 1 & 1 \\
Untypeable & 0 & 1 & 0 & 23 & 18 \\
Total & 1 & 14 & 3 & \\
\hline
\end{tabular}

\footnotetext{
${ }^{1}$ Number of operations in which the serogroup was identified only in a milk sample.

${ }^{2}$ Number of operations in which the serogroup was identified only in a filter sample.

${ }^{3}$ Number of operations in which the serogroup was identified in both the milk and the milk filter sample.

${ }^{4}$ Two serogroups were isolated from 1 filter sample.

${ }^{5}$ Atypical phenotype derived from the Doumith et al. (2004) serogroup PCR method.
} 
tributed to pathogens harbored by dairy animals. In a study of data from 2004 to 2011, Afema et al. (2015) found that Montevideo, Newport, and Typhimurium were among the most frequently isolated serovars in human clinical isolates from Washington State, as well as clinical and nonclinical dairy isolates from the Pacific Northwest. Similarly, Rodriguez-Rivera et al. (2014) identified common Salmonella serovars in samples from subclinical cattle, dairy farm environmental samples, and human clinical samples in New York from October 2007 to August 2009. Among cattle and farm isolates, Cerro and Kentucky were the most prevalent serovars, followed by Newport and Typhimurium. These serovars, along with Montevideo, were among the 12 serovars in which identical pulsed-field gel electrophoresis types were identified in human isolates, as well as cattle or environmental isolates. Although cases have been reported, Cerro and Kentucky are uncommonly isolated from humans. Conversely, Newport, Typhimurium, and Montevideo are among the most frequently isolated serotypes associated with human salmonellosis (Rodriguez-Rivera et al., 2014; CDC, 2016e).

Salmonella serovar Dublin is a particular concern in the dairy industry because it can cause severe illness in calves and adult cattle, and latent carriers can excrete high numbers of the organism in their feces, resulting in significant economic and production losses, as well as high animal morbidity and mortality (Hinton, 1977; Nielsen et al., 2004). Dublin is also the most common serotype isolated from bovine clinical samples by the National Veterinary Services Laboratories (CDC, 2014). Although it is a bovine-adapted serovar, Salmonella Dublin has also been shown to cause severe, invasive disease in humans (Fierer, 1983). In a study of FoodNet salmonellosis cases from 1996 to 2006, Jones et al. (2008) found that, although only $0.2 \%$ of Salmonella infections were Salmonella Dublin, these infections had the greatest hospitalization rate $(67.0 \%)$ among the 57 serotypes reported with at least 50 identified cases. Based on an analysis of 5 US surveillance systems, Harvey et al. (2017) determined that the Salmonella Dublin incidence rate of infection in humans has been increasing faster than the incidence rate with other Salmonella. Salmonella Dublin has been isolated from ground beef, in which it is one of the most frequently isolated Salmonella serotypes, according to the USDA Food Safety Inspection Service and the 2012-2013 NARMS Integrated Report (FDA, 2015; USDA FSIS, 2016b). The NARMS reports indicate that Salmonella Dublin isolates from recent years have been resistant to multiple antimicrobials; isolates from human and cattle sources have been identified as ceftriaxone resistant (FDA, 2016b), and isolates from ground beef have been resistant to as many as 12 antimicrobials (FDA, 2016a).
This trend in increased resistance was also noted in Dublin isolates from humans (Harvey et al., 2017).

Because isolating Salmonella Dublin using traditional culture protocols can present challenges, we designed a real-time PCR assay to target this serovar and Salmonella Dublin was detected in 4 samples from 4 operations. As with other serotypes, Salmonella Dublin was more frequently detected in filters (3 samples) than in BTM (1 sample). Of the 2 PCR-positive samples from which Dublin was not isolated, Kentucky and Oranienburg were isolated from the 2 respective filters and these strains may have overwhelmed, in number, the Dublin isolates in the samples.

The observed prevalence of antimicrobial resistance in Salmonella isolates was relatively low in the 2002, 2007, and 2014 NAHMS Dairy studies. In the 2014 isolates, resistance to one or more antimicrobial agents was detected in $13.9 \%$ of Salmonella isolates that were tested, whereas, in previous studies, $16.2 \%$ (2007) and $20.7 \%$ (2002) of isolates were resistant to 1 or more antimicrobials (Van Kessel et al., 2013). A similar level of resistance was reported by Rodriguez-Rivera et al. (2016), in a 2-mo study of Salmonella isolated from environmental samples and fecal samples from cull dairy cows in Texas: $11.9 \%$ of environmental isolates and $19.5 \%$ of fecal isolates were resistant.

Resistant Salmonella isolates were recovered from only 7 operations in this study but that is still remarkable; antimicrobial resistance, especially to cephalosporins such as cefoxitin, ceftiofur, and ceftriaxone, can have a big effect on the outcome of infections. Cephalosporins are among the last-resort treatments for many human bacterial infections, so infections with resistant strains can limit treatment options. Salmonella Newport, Muenchen, and Dublin isolates from the NAHMS Dairy 2014 study were resistant to cephalosporins, whereas Newport and Typhimurium isolates from the 2007 study, and Dublin and Newport from the 2002 study, were cephalosporin resistant. Antimicrobial resistance phenotypes were comparable for Salmonella isolates across the 2002, 2007, and 2014 Dairy studies, with common resistance profiles of the ACSSuT phenotype (AMP/CHL/STR/sulfonamides/TET), plus cephalosporin resistance. Extensive antimicrobial resistance, especially in serovars associated with severe infections in humans and in animals, warrants further monitoring.

\section{E. coli}

Escherichia coli is also a very diverse species, and it is mostly an avirulent commensal member of the mammalian gut. However, enteropathogenic, STEC, and enterohemorrhagic (EHEC) strains can cause serious human illness. These strains attach to the intestinal lining 
and invade host cells that subsequently absorb Shiga toxins. Enterohemorrhagic strains, in particular, can cause bloody diarrhea and hemolytic uremic syndrome (Mathusa et al., 2010). Treatment of STEC and EHEC infections has been controversial, and antimicrobial therapies have been contraindicated because they cause the release of Shiga-toxins and further clinical manifestations (Nguyen and Sperandio, 2012). As a last-resort option, colistin is available, but cases, though few in number, of colistin-resistant infections have been documented in China and in the United States (Liu et al., 2016; McGann et al., 2016).

Within the pathogenic E. coli population, Shigatoxin genes $s t x_{1}$ and $s t x_{2}$ are known to be cytotoxic and both the E. coli attachment-effacement (eaeA) and the gamma allele of the translocated intimin receptor $(\gamma$-tir) gene facilitate invasion of the bacterium into the intestine (Caprioli et al., 2005; Nguyen and Sperandio, 2012). Cases of hemolytic uremic syndrome are linked to expression of $s t x_{2}$, either independently, or, more so, in conjunction with eaeA expression, and samples harboring 1 or both Shiga-toxin genes, in addition to eaeA and $\gamma$-tir, may be associated with the E. coli $\mathrm{O} 157$ phenotype (Law, 2000; Werber et al., 2003; Karns et al., 2007; Mathusa et al., 2010).

In this study, a combination of stx $x_{2}$ eaeA, and $\gamma$-tir genes, which are associated with E. coli O157, was found in 0.5 and $1.1 \%$ of operations in BTM, and in 6.6 and $6.3 \%$ of operations in filters (in 2014 and 2007, respectively). Similarly, this phenotype was observed in the 2007 study in 1.1 and $6.3 \%$ of operations in BTM and filters, respectively (Van Kessel et al., 2011). The prevalence of eaeA, the only E. coli virulence gene targeted in all samples in the 2002 study, was also similar in the milk across all 3 studies, and in the filters of the 2007 and 2014 studies (Karns et al., 2007; Van Kessel et al., 2011).

Although EHEC indicator genes were not frequently detected in BTM, some pathogenic E. coli such as O157:H7 can cause serious, and even fatal infections. Foodborne outbreaks of E. coli have been well documented in the United States. FoodNet 2015 data indicate that 465 cases of STEC O157 and 807 cases of STEC non-O157 infections were reported, and together these represented $6.3 \%$ of all laboratory-confirmed cases of foodborne illness (CDC, 2017a). Multiple outbreaks of E. coli O157:H7, a particularly virulent EHEC with a very low infectious dose, have been associated with beef and ground beef, aged raw milk cheeses, and raw milk and colostrum - some resulting in children being hospitalized with hemolytic uremic syndrome (CDC, 2007, 2008, 2017b; Guh et al., 2010; McCollum et al., 2012).

\section{Listeria}

Although multiple Listeria species may circulate in the dairy farm environment, L. monocytogenes is the species of human public health significance (Perry and Donnelly, 1990; CDC, 2016a). In recent years, multiple outbreaks due to consumption of unpasteurized milk, soft cheeses, ice cream, frozen vegetables, and cantaloupe (CDC, 2016b) have increased public awareness of this pathogen. In 2015 the CDC's FoodNet recorded 116 cases of listeriosis, of which $111(95.7 \%)$ cases lead to hospitalization (CDC, 2017a). In the previous year, 2 cases were associated with raw chocolate milk from a single source; both cases lead to hospitalizations, and 1 patient died as a result of the infection (CDC, 2016c). Similarly, a recent outbreak attributed to raw milk cheese has resulted in 2 deaths among the 8 patients who were hospitalized (CDC, 2017c).

The prevalence of $L$. monocytogenes was lower in this study than in previous studies. Listeria monocytogenes was isolated from $3.0 \%$ of operations, whereas this pathogen was isolated from 7.1 and $6.5 \%$ of operations in the 2007 and 2002 studies, respectively. Among the 12 recognized $L$. monocytogenes serotypes, $1 / 2 \mathrm{a}, 1 / 2 \mathrm{~b}$, and $4 \mathrm{~b}$ are the most frequently associated with human illness, and most Listeria outbreaks (95\%) are associated with serotype 4b (CDC, 2016d). Based on PCR analysis, the majority of the L. monocytogenes isolates from the BTM and filters were serogroups 1/2a (37.2\%) and $1 / 2 \mathrm{~b}(23.3 \%)$, and $4 \mathrm{~b}(20.9 \%)$, was similarly observed in the 2007 study. Despite this relatively low prevalence, L. monocytogenes can grow at refrigeration temperatures and has a high burden of human illness, so even low levels pose a risk to consumers (Allerberger and Wagner, 2010).

\section{Operation Characteristics}

The US dairy industry is very diverse with respect to herd size and management characteristics. These operation traits are often correlated with each other, but many other factors influence management choices including region, climate, and local economics. It would be useful to consider the effect of differing operation characteristics on contamination of BTM; however, the current study size (234 operations) is somewhat limiting. No significant differences were detected in Salmonella or L. monocytogenes prevalence in BTM and filters from organic and conventional operations. However, there were only 19 organic operations and that limited the power of this comparison. Previously Salmonella was isolated more frequently from operations in the east than from the west (Ruzante et al., 2010), but 
no differences based on geographic location were noted in this study. Salmonella was more frequently isolated from large herds than from small or medium herds, and this was also observed in the NAHMS Dairy 2007 study (Ruzante et al., 2010; USDA APHIS, 2011). Listeria monocytogenes was more prevalent in the BTM and filters from large and medium herds than in small herds. The trend in US dairy operations is toward increasing herd size, and one may infer that a concomitant increase in pathogen prevalence in BTM will occur. More information is needed to identify strategies for reducing the prevalence of zoonotic bacteria in dairy herds and minimizing the contamination of the BTM.

\section{CONCLUSIONS}

This study provides a snapshot of pathogen prevalence in BTM and milk filters on representative dairy operations in the United States. Salmonella contamination was found in almost 1 in $5(18 \%)$ operations including some strains that were resistant to multiple antimicrobials. Although the prevalence of L. monocytogenes, antimicrobial-resistant salmonellae, and pathogenic E. coli was relatively low, the additive risk of these zoonotic pathogens further reinforces the potential public health risk in consuming nonpasteurized milk or dairy products.

\section{ACKNOWLEDGMENTS}

The authors thank the participating producers, veterinary medial officers, and animal health technicians who conducted the study, and Laura Del Collo (USDA-ARS, Beltsville, MD) for technical assistance. The mention of a trade name, proprietary product, or specific equipment does not constitute a guarantee or warranty by the USDA and does not imply approval to the exclusion of other products that might be suitable.

\section{REFERENCES}

Afema, J. A., A. E. Mather, and W. M. Sischo. 2015. Antimicrobial resistance profiles and diversity in Salmonella from humans and cattle, 2004-2011. Zoonoses Public Health 62:506-517. https://doi .org/10.1111/zph.12172.

Allerberger, F., and M. Wagner. 2010. Listeriosis: A resurgent foodborne infection. Clin. Microbiol. Infect. 16:16-23. https://doi.org/ 10.1111/j.1469-0691.2009.03109.x.

Andrews, W. H., H. Wang, A. Jacobson, and T. Hammack. 2016. Salmonella. In Bacteriological Analytical Manual, 8th ed., Revision A. Center for Food Safety and Applied Nutrition, US FDA, College Park, MD. Accessed Oct. 23, 2017. https://www.fda.gov/ Food/FoodScienceResearch/LaboratoryMethods/ucm070149.htm.

Caprioli, A., S. Morabiot, and H. Brugère. 2005. Enterohaemorrhagic Escherichia coli: Emerging issues on virulence and modes of transmission. Vet. Res. 36:289-311. https://doi.org/10.1051/vetres: 2005002 .
CDC (Centers for Disease Control and Prevention). 2007. March 2. Escherichia coli O157:H7 infection associated with drinking raw milk-Washington and Oregon, November-December 2005. MMWR 56:165-167.

CDC (Centers for Disease Control and Prevention). 2008. June 13. Escherichia coli $\mathrm{O} 157: \mathrm{H} 7$ infections in children associated with raw milk and raw colostrums from cows-California, 2006. MMWR $57: 625-628$.

CDC (Centers for Disease Control and Prevention). 2014. National Salmonella Surveillance Annual Report, 2012. US Department of Health and Human Services, CDC, Atlanta, GA.

CDC (Centers for Disease Control and Prevention). 2016a. Listeria (Listeriosis). Information for Health Professionals and Laboratories. Accessed May 17, 2017. https://www.cdc.gov/listeria/ technical.html.

CDC (Centers for Disease Control and Prevention). 2016b. Listeria outbreaks. Accessed May 17, 2017. http://www.cdc.gov/listeria/ outbreaks/index.html

CDC (Centers for Disease Control and Prevention). 2016c. March 18. Multistate outbreak of listeriosis linked to raw milk produced by Miller's organic farm in Pennsylvania. Accessed Jun. 7, 2017. http://www.cdc.gov/listeria/outbreaks/raw-milk-03-16/.

CDC (Centers for Disease Control and Prevention). 2016d. National enteric disease surveillance: The Listeria initiative. Accessed May 17, 2017. https://www.cdc.gov/listeria/pdf/ListeriaInitiativeOverview -508.pdf.

CDC (Centers for Disease Control and Prevention). 2016e. National Salmonella Surveillance Annual Report, 2013. US Department of Health and Human Services, CDC, Atlanta, GA.

CDC (Centers for Disease Control and Prevention). 2017a. Foodborne Diseases Active Surveillance Network (FoodNet): FoodNet 2015 Surveillance Report (Final Data). US Department of Health and Human Services, CDC, Atlanta, GA.

CDC (Centers for Disease Control and Prevention). 2017b. List of selected multistate foodborne outbreak investigations; list of selected outbreak investigations, by pathogen. Accessed Jun. 3, 2017. http://www.cdc.gov/foodsafety/outbreaks/multistate-outbreaks/ outbreaks-list.html.

CDC (Centers for Disease Control and Prevention). 2017c. Multistate outbreak of listeriosis linked to soft raw milk cheese made by Vulto Creamery (Final update). Accessed May 31, 2017. https://www .cdc.gov/listeria/outbreaks/soft-cheese-03-17/index.html.

Clinical and Laboratory Standards Institute. 2012. Performance Standards for Antimicrobial Susceptibility Testing. Twenty-Second Informational Supplement, M100-S22. CLSI, Wayne, PA.

Crim, S. M., P. M. Griffin, R. Taux, E. P. Marder, D. Gilliss, A. B. Cronquist, M. Cartter, M. Tobin-D'Angelo, D. Blythe, K. Smith, S. Lathrop, S. Zansky, P. R. Cieslak, J. Dunn, K. G. Holt, B. Wolpert, and O. L. Henao. 2015. Preliminary incidence and trends of infection with pathogens transmitted commonly through foodFoodborne Diseases Active Surveillance Network, 10 U.S. Sites, 2006-2014. MMWR Morb. Mortal. Wkly. Rep. 64:495-499.

Del Collo, L. P., J. S. Karns, D. Biswas, J. E. Lombard, B. J. Haley, R. C. Kristensen, C. A. Kopral, C. P. Fossler, and J. S. Van Kessel. 2017. Prevalence, antimicrobial resistance, and molecular characterization of Campylobacter spp. in bulk tank milk and milk filters from US dairies. J. Dairy Sci. 100:3470-3479. https://doi.org/10 .3168/jds.2016-12084.

Doumith, M., C. Buchrieser, P. Glaser, C. Jacquet, and P. Martin. 2004. Differentiation of the major Listeria monocytogenes serovars by multiplex PCR. J. Clin. Microbiol. 42:3819-3822. https://doi .org/10.1128/JCM.42.8.3819-3822.2004.

FDA (Food and Drug Administration). 2015. NARMS Integrated Report, 2012-2013. Accessed Sep. 16, 2016. http://www.fda.gov/downloads/ AnimalVeterinary/SafetyHealth/AntimicrobialResistance/ NationalAntimicrobialResistanceMonitoringSystem/UCM453398 .pdf.

FDA (Food and Drug Administration). 2016a. April 28. FDA NARMS Retail Meat Interim Report for Salmonella shows encouraging early trends continue; includes whole genome sequencing data 
for the first time Accessed Sep. 16, 2016. http://www.fda.gov/ animalveterinary/newsevents/cvmupdates/ucm498038.htm.

FDA (Food and Drug Administration). 2016b. Reports and Data. 2014 NARMS Integrated Report. Highlights. Accessed Jun. 1, 2017. http://www.fda.gov/ AnimalVeterinary/SafetyHealth/AntimicrobialResistance/ NationalAntimicrobialResistanceMonitoringSystem/ucm059103 .htm.

Fierer, J. 1983. Invasive Salmonella Dublin infections associated with drinking raw milk. West. J. Med. 138:665-669.

Guh, A., Q. Phan, N. Randall, K. Purviance, E. Milardo, S. Kinney, P. Mshar, W. Kasacek, and M. Cartter. 2010. Outbreak of Escherichia coli O157 associated with raw milk, Connecticut, 2008. Clin. Infect. Dis. 51:1411-1417. https://doi.org/10.1086/657304.

Harvey, R. R., C. R. Friedman, S. M. Crim, M. Judd, K. A. Barrett, B. Tolar, J. P. Folster, P. M. Griffin, and A. C. Brown. 2017. Epidemiology of Salmonella enterica serotype Dublin infections among humans, United States, 1968-2013. Emerg. Infect. Dis. 23:14931501. https://doi.org/10.3201/eid2309.170136.

Hinton, M. 1977. The diagnostics of Salmonella abortion in cattle with particular reference to Salmonella Dublin. A review. J. Hyg. (Lond.) 79:25-38.

Huang, B., N. Fang, K. Dimovski, X. Wang, G. Hogg, and J. Bates. 2011. Observation of a new pattern in serogroup-related PCR typing of Listeria monocytogenes $4 \mathrm{~b}$ isolates. J. Clin. Microbiol. 49:426-429. https://doi.org/10.1128/JCM.01207-10.

Jones, T. F., L. A. Ingram, P. R. Ceislak, D. J. Vugia, M. TobinD'Angelo, S. Hurd, C. Medus, A. Cronquist, and F. J. Angulo. 2008. Salmonellosis outcomes differ substantially by serotype. J. Infect. Dis. 198:109-114. https://doi.org/10.1086/588823.

Karns, J. S., J. S. Van Kessel, B. J. McCluskey, and M. L. Perdue. 2005. Prevalence of Salmonella enterica in bulk tank milk from US dairies as determined by polymerase chain reaction. J. Dairy Sci. 88:3475-3479. https://doi.org/10.3168/jds.S0022-0302(05)73031 -9 .

Karns, J. S., J. S. Van Kessel, B. J. McClusky, and M. L. Perdue. 2007. Incidence of Escherichia coli $\mathrm{O} 157: \mathrm{H} 7$ and E. coli virulence factors in US bulk tank milk as determined by polymerase chain reaction. J. Dairy Sci. 90:3212-3219. https://doi.org/10.3168/jds.2006-009.

Katafiasz, A. R., and P. Bartlett. 2012. Motivation for unpasteurized milk consumption in Michigan, 2011. Food Prot. Trends 32:124128.

Laksanalamai, P., B. Huang, J. Sabo, L. S. Burall, S. Zhao, J. Bates, and A. R. Datta. 2014. Genomic characterization of novel Listeria monocytogenes serotype 4b variant strains. PLoS One 9:e89024. https://doi.org/10.1371/journal.pone.0089024.

Langer, A. J., T. Ayers, J. Grass, M. Lynch, F. J. Angulo, and B. E. Mahon. 2012. Nonpasteurized dairy products disease outbreaks, and state laws-United States, 1993-2006. Emerg. Infect. Dis. 18:385-391. https://doi.org/10.3201/eid1803.111370.

Latorre, A. A., A. K. Pradhan, J. S. Van Kessel, J. S. Karns, K. J. Boor, D. H. Rice, K. J. Mangione, Y. T. Gröhn, and Y. H. Schukken. 2011. Quantitative risk assessment of listeriosis due to consumption of raw milk. J. Food Prot. 74:1268-1281. https://doi .org/10.4315/0362-028X.JFP-10-554.

Law, D. 2000. Virulence factors of Escherichia coli O157 and other Shiga toxin-prodcuing E. coli. J. Appl. Microbiol. 88:729-745. https://doi.org/10.1046/j.1365-2672.2000.01031.x.

Leclercq, A., V. Chenal-Francisque, H. Dieye, T. Cantinelli, R. Drali, S. Brisse, and M. Lecuit. 2011. Characterization of the novel Listeria monocytogenes PCR serogrouping profile Ivb-v1. Int. J. Food Microbiol. 147:74-77. https://doi.org/10.1016/j.ijfoodmicro.2011 .03 .010 .

Liu, Y., Y. Wang, T. R. Walsh, L. Yi, R. Zhang, J. Spencer, Y. Doi, G. Tian, B. Dong, X. Huang, L. Yu, D. Gu, H. Ren, X. Chen, L. Lv, D. He, H. Zhou, Z. Liang, J. Liu, and J. Shen. 2016. Emergence of plasmid-mediated colistin resistance mechanism MCR-1 in animals and human beings in China: A microbiological and molecular biological study. Lancet Infect. Dis. 16:161-168. https://doi.org/10 .1016/S1473-3099(15)00424-7.
Mathusa, E. C., Y. Chen, E. Enache, and L. Hontz. 2010. Non-O157 shiga toxin-producing Escherichia coli in foods. J. Food Prot. 73:1721-1736. https://doi.org/10.4315/0362-028X-73.9.1721.

McCollum, J. T., N. J. Williams, S. W. Beam, S. Cosgrove, P. J. Ettestad, T. S. Ghosh, A. C. Kimura, L. Nguyen, S. G. Stroika, R. L. Vogt, A. K. Watkins, J. R. Weiss, I. T. Williams, and A. B. Cronquist. 2012. Multistate outbreak of Escherichia coli O157:H7 infections associated with in-store sampling of an aged raw-milk Gouda cheese, 2010. J. Food Prot. 75:1759-1765. https://doi.org/ 10.4315/0362-028X.JFP-12-136.

McGann, P., E. Snesrud, R. Maybank, B. Corey, A. C. Ong, R. Clifford, M. Hinkle, T. Whitman, E. Lesho, and K. E. Schaecher. 2016. Escherichia coli harboring $m c r-1$ and bla $a_{\mathrm{CTX}-\mathrm{M}}$ on a novel IncF plasmid: First report of $m c r-1$ in the United States. Antimicrob. Agents Chemother. 60:4420-4421. https://doi.org/10.1128/ AAC.01103-16.

Mungai, E. A., C. B. Behravesh, and L. H. Gould. 2015. Increased outbreaks associated with nonpasteurized milk, United States, 2007-2012. Emerg. Infect. Dis. 21:119-122. https://doi.org/10 .3201/eid2101.140447.

NASDA (National Association of State Departments of Agriculture). 2011. July 19. NASDA releases raw milk survey. Press release. Accessed Sep. 8, 2016. http://www.nasda.org/file.aspx?id=3916.

Nguyen, Y., and V. Sperandio. 2012. Enterohemorrhagic E. coli (EHEC) pathogenesis. 2012. Front. Cell. Infect. Microbiol. 2:90. https://doi.org/10.3389/fcimb.2012.00090.

Nielsen, L. R., Y. H. Schukken, Y. T. Gröhn, and A. K. Ersbøll. 2004 Salmonella Dublin infection in dairy cattle: Risk factors for becoming a carrier. Prev. Vet. Med. 65:47-62. https://doi.org/10.1016/j prevetmed.2004.06.010.

Oliver, S. P., K. J. Boor, S. C. Murphy, and S. E. Murinda. 2009. Food safety hazards associated with consumption of raw milk. Foodborne Pathog. Dis. 6:793-806. https://doi.org/10.1089/fpd.2009 .0302 .

Perry, C. M., and C. W. Donnelly. 1990. Incidence of Listeria monocytogenes in silage and its subsequent control by specific and nonspecific antagonism. J. Food Prot. 53:642-647. https://doi.org/10 4315/0362-028X-53.8.642

Phillippy, A. M., J. A. Mason, K. Ayanbule, D. D. Sommer, E. Taviani, A. Hug, R. R. Colwell, I. T. Knight, and S. L. Salzberg. 2007. Comprehensive DNA signature discovery and validation. PLOS Comput. Biol. 3:e98. https://doi.org/10.1371/journal.pcbi .0030098

Robinson, T. J., J. M. Scheftel, and K. E. Smith. 2014. Raw milk consumption among patients with non-outbreak-related enteric infections, Minnesota, USA, 2001-2010. Emerg. Infect. Dis. 20:38-44. https://doi.org/10.3201/eid2001.120920.

Rodriguez-Rivera, L. D., K. J. Cummings, G. H. Loneragan, S. C. Rankin, D. L. Hanson, W. M. Leone, and T. S. Edrington. 2016. Salmonella prevalence and antimicrobial susceptibility among dairy farm environmental samples collected in Texas. Foodborne Pathog. Dis. 13:205-211. https://doi.org/10.1089/fpd.2015.2037.

Rodriguez-Rivera, L. D., E. M. Wright, J. D. Siler, M. Elton, K. J. Cummings, L. D. Warnick, and M. Wiedmann. 2014. Subtype analysis of Salmonella isolated from subclinically infected dairy cattle and dairy farm environments reveals the presence of both human-and bovine-associated subtypes. Vet. Microbiol. 170:307316. https://doi.org/10.1016/j.vetmic.2014.02.013.

Ruzante, J. M., J. E. Lombard, B. Wagner, C. P. Fossler, J. S. Karns, J. A. S. Van Kessel, and I. A. Gardner. 2010. Factors associated with Salmonella presence in environmental samples and bulk tank milk from US dairies. Zoonoses Public Health 57:1-9. https://doi .org/10.1111/j.1863-2378.2010.01333.x.

Scallan, E., R. M. Hoekstra, F. J. Angulo, R. V. Tauxe, M. Widdowson, S. L. Roy, J. L. Jones, and P. M. Griffin. 2011. Foodborne illness acquired in the United States-Major pathogens. Emerg. Infect. Dis. 17:7-15. https://doi.org/10.3201/eid1701.091101p1.

Schleif, R. F., and P. C. Wensink. 1981. Practical Methods in Molecular Biology. Spring-Verlag, New York, NY.

USDA APHIS (Animal and Plant Health Inspection Service). 1998. E. coli O157 and Salmonella- Status on US Dairy Operations. Ac- 
cessed Jun. 6, 2017. https://www.aphis.usda.gov/animal_health/ nahms/dairy/downloads/dairy96/Dairy96_is_Ecoli_Salm.pdf.

USDA APHIS (Animal and Plant Health Inspection Service). 2011. Salmonella, Listeria, and Campylobacter on U.S. Dairy Operations, 1996-2007. USDA-APHIS-VS, CEAH. Fort Collins, CO. Accessed Jun. 6, 2017. https://www.aphis.usda.gov/animal_health/nahms/ dairy/downloads/dairy07/Dairy07_ir_Food_safety.pdf.

USDA FSIS (Food Safety and Inspection Service). 2016a. Ground beef and food safety. Accessed Mar. 29, 2017. https://www.fsis.usda .gov/wps/portal/fsis/topics/food-safety-education/get-answers/ food-safety-fact-sheets/meat-preparation/ground-beef-and-food -safety/CT_Index.

USDA FSIS (Food Safety and Inspection Service). 2016b. Serotypes profile of Salmonella isolates from meat and poultry products, January 1998 through December 2014. Accessed Sep. 9, 2016. http://www.fsis.usda.gov/wps/wcm/connect/3866026a-582d-4f0e -a8ce-851b39c7390f/Salmonella-Serotype-Annual-2014.pdf?MOD $=$ AJPERES

Van Kessel, J. S., J. S. Karns, L. Goski, B. J. McCluskey, and M. L. Perdue. 2004. Prevalence of Salmonellae, Listeria monocytogenes, and fecal coliforms in bulk tank milk on US dairies. J. Dairy Sci. 87:2822-2830. https://doi.org/10.3168/jds.S0022-0302(04)73410 -4 .

Van Kessel, J. S., J. S. Karns, J. E. Lombard, and C. A. Kopral. 2011. Prevalence of Salmonella enterica, Listeria monocytogenes, and Escherichia coli virulence factors in bulk tank milk and in-line filters from U.S. dairies. J. Food Prot. 74:759-768. https://doi .org/10.4315/0362-028X.JFP-10-423.

Van Kessel, J. S., J. S. Karns, D. R. Wolfgang, E. Hovingh, B. M. Jayarao, C. P. Van Tassell, and Y. H. Schukken. 2008. Environmental sampling to predict fecal prevalence of Salmonella in an intensively monitored dairy herd. J. Food Prot. 71:1967-1973. https://doi.org/10.4315/0362-028X-71.10.1967.

Van Kessel, J. S., J. S. Karns, D. R. Wolfgang, E. Hovingh, and Y. H. Schukken. 2007. Longitudinal study of a clonal, subclinical out- break of Salmonella enterica ssp. enterica serovar Cerro in a U.S. dairy herd. Foodborne Pathog. Dis. 4:449-461. https://doi.org/10 $.1089 /$ fpd.2007.0033.

Van Kessel, J. S., J. S. Karns, D. R. Wolfgang, E. Hovingh, and Y. H. Schukken. 2012. Dynamics of Salmonella serotype shifts in an endemically infected dairy herd. Foodborne Pathog. Dis. 9:319-324. https://doi.org/10.1089/fpd.2011.1054.

Van Kessel, J. S., J. Sonnier, S. Zhao, and J. S. Karns. 2013. Antimicrobial resistance of Salmonella enterica isolates from bulk tank milk and milk filters in the United States. J. Food Prot. 76:18-25. https://doi.org/10.4315/0362-028X.JFP-12-263.

Veling, J., H. W. Barkema, J. van der Schans, F. van Zijderveld, and J. Verhoeff. 2002. Herd-level diagnosis for Salmonella enterica ssp. enterica serovar Dublin infection in bovine dairy herds. Prev. Vet. Med. 53:31-42. https://doi.org/10.1016/S0167-5877(01)00276-8.

Ward, T. J., L. Gorski, M. K. Borucki, R. E. Mandrell, J. Hutchins, and K. Pupedis. 2004. Intraspecific phylogeny and lineage group identification based on the prfA virulence gene cluster of Listeria monocytogenes. J. Bacteriol. 186:4994-5002. https://doi.org/10 .1128/JB.186.15.4994-5002.2004.

Wells, S. J., P. J. Fedorka-Cray, D. A. Dargatz, K. Ferris, and A. Green. 2001. Fecal shedding of Salmonella spp. by dairy cows on farm and at cull cow markets. J. Food Prot. 64:3-11. https://doi .org/10.4315/0362-028X-64.1.3.

Werber, D., A. Fruth, U. Buchholz, R. Prager, M. H. Kramer, A Ammon, and H. Tschäpe. 2003. Strong association between Shiga toxin-producing Escherichia coli $\mathrm{O} 157$ and virulence genes st $x_{2}$ and eae as possible explanation for predominance of serogroup O157 in patients with haemolytic uraemic syndrome. Eur. J. Clin. Microbiol. Infect. Dis. 22:726-730. https://doi.org/10.1007/s10096-003 $-1025-0$.

Ye, J., G. Coulouris, I. Zaretskaya, I. Cutcutache, S. Rozen, and T. L. Madden. 2012. Primer-BLAST: A tool to design target-specific primers for polymerase chain reaction. BMC Bioinformatics 13:134. https://doi.org/10.1186/1471-2105-13-134. 